\title{
FORMAÇÃo CONTINUAdA E INTERVENÇõES PEDAGÓGICAS: ENSINO E APRENDIZAGEM NA ESCOLA ESTADUAL IVONE BORKOWSKI DE LIMA
}

\author{
CONTINUING EDUCATION AND PEDAGOGICAL INTERVENTIONS: TEACHING \\ AND LEARNING AT IVONE BORKOWSKI DE LIMA STATE SCHOOL
}

DOI: 10.23926/RPD.2526-2149.2020.v5.n2.p1355-1373.id749

\section{Geovana Salustiano Couto \\ Mestranda em Educação (UNEMAT) \\ Professora da Educação \\ Básica (SEDUC-MT) \\ geovana.geosal@gmail.com}

\section{Valdiceia Moreira \\ Ribeiro \\ Mestranda em Educação \\ (UNEMAT) \\ Professora da Educação \\ Básica (SEDUC-MT) \\ valdiceiamax@gmail.com}

Laudemir Luiz Zart

Doutorado em Política

Científica e Tecnológica

(UNICAMP)

Professor da Universidade do

Estado de Mato Grosso

(UNEMAT)

laudemirzart13@yahoo.com. $\underline{b r}$

\section{Heloisa Salles Gentil}

Doutorado em Educação (UFRGS)

Professora da Universidade do Estado de Mato Grosso

(UNEMAT)

logenti12@gmail.com
Resumo: O objetivo deste artigo é analisar as práticas pedagógicas realizadas pelos docentes de uma escola no campo a partir do projeto de formação continuada da/na escola, estruturado por meio do orientativo para as escolas estaduais do Estado de Mato Grosso, elaborado pela Secretaria de Estado de Educação SEDUC-MT no ano letivo de 2019, visando melhorar o processo de ensino e aprendizagem, por meio das intervenções pedagógicas realizadas pelos professores no desenvolvimento de suas práticas pedagógicas. Trata-se de uma pesquisa qualitativa, cujos dados foram obtidos mediante observação e análise documental. Apresentamos as intervenções pedagógicas adotadas pelos professores para melhorar a motivação dos educandos e os resultados da educação escolar. Evidenciamos que as intervenções pedagógicas realizadas pelos professores alcançaram resultados satisfatórios quanto às metas propostas - elevar o índice de aprovação do ensino médio para 100\%; zerar a progressão parcial; tornar o ambiente escolar mais agradável, atrativo e lúdico.

Palavras-chave: Intervenções Pedagógicas. Práticas Pedagógicas. Formação Continuada.

\begin{abstract}
The aim of this article is to analyze the pedagogical practices carried out by the teachers of a school in the countryside based on the continuing education project of at / in the school, structured through the guidance for the state schools of Mato Grosso, prepared by the State Secretariat of Education SEDUC-MT in the academic year of 2019, aiming to improve the teaching and learning process, through pedagogical interventions carried out by teachers in the development of their pedagogical practices. It is a qualitative research, whose data were obtained upon observation and documentary analysis. We present the pedagogical interventions adopted by teachers to improve students' motivation and the results of school education. We evidenced that the pedagogical interventions carried out by the teachers achieved satisfactory results in relation to the proposed goals - to raise the high school approval rate to $100 \%$; zero partial progression; make the school environment more pleasant, attractive and playful.
\end{abstract}

Keywords: Pedagogical Interventions. Pedagogical Practices. Continuing Education. 


\section{INTRODUÇÃO}

Neste artigo abordaremos as relações estabelecidas entre a formação continuada e as intervenções pedagógicas, tendo como foco os resultados alcançados durante o processo de ressignificação das relações de ensino e aprendizagem dos educandos da Escola Estadual Ivone Borkowski de Lima, no município de Nova Canaã do Norte - MT.

O estudo foi desenvolvido para analisar o processo de formação continuada, com a finalidade de compreender como ocorre a organização dos estudos teóricos e práticos realizados pelos professores e como estes contribuem para o aperfeiçoamento das práticas pedagógicas.

O presente artigo traz resultados de uma pesquisa desenvolvida em uma escola no campo no transcorrer do ano letivo de 2019 com a seguinte questão-problema: como foram desenvolvidas as práticas pedagógicas a partir do projeto de formação continuada e com implementação das intervenções pedagógicas na Escola Estadual Ivone Borkowski de Lima?

Tivemos como objetivo geral analisar as práticas pedagógicas realizadas pelos docentes de uma escola no campo a partir do projeto de formação continuada da/na escola, estruturado por meio do orientativo para as escolas estaduais do Estado de Mato Grosso, elaborado pela Secretaria de Estado de Educação SEDUC-MT no ano letivo de 2019, visando melhorar o processo de ensino e aprendizagem, por meio das intervenções pedagógicas realizadas pelos professores no desenvolvimento de suas práticas pedagógicas. Procuramos evidenciar quais foram as intervenções pedagógicas adotadas pelos profissionais da escola para melhorar a motivação do educando e os resultados da educação escolar.

Dentre as metas evidenciadas pela escola para proporcionar a melhoria na qualidade da educação dos estudantes, analisamos as intervenções pedagógicas realizadas para atingir as seguintes metas propostas pelo próprio corpo docente: elevar o índice de aprovação do Ensino Médio para 100\%; zerar a progressão parcial e tornar o ambiente escolar mais agradável, atrativo e lúdico.

Nesse sentido, a escola obteve resultados satisfatórios, pois conseguiu atingir um índice de aprovação de 93,75\% dos estudantes matriculados no Ensino Médio, porém essa porcentagem sobe para $95,60 \%$ quando consideramos somente a escola sede que inclui educandos do ensino regular e EJA e se considerarmos somente o Ensino Médio regular, obteve-se um índice de $100 \%$ dos alunos desta etapa de ensino aprovados em 2019. Com relação à progressão parcial, a escola conseguiu diminuir este índice para $8,7 \%$, haja vista que no ano anterior era de $19,64 \%$. Quanto a terceira meta, os docentes enfatizaram que esse objetivo foi 
alcançado, visto que conseguiram proporcionar momentos de diversão, alegria, parceria, coletividade, comunicação, cooperação além de fortalecer as relações socioafetivas.

Para tanto, desenvolvemos uma pesquisa qualitativa na qual coletamos os dados por meio de observação durante os encontros de formação continuada e realizamos análise documental.

O suporte teórico deste estudo encontra-se em Freire (2013, 2017), Veiga (1992), Franco (2016), Bento (1989), Machado (2009), Leite (2008), Imbernón (2010), Marcelo Garcia (1999).

Partimos do pressuposto que o dia-a-dia da sala de aula é entendido como um ambiente de desenvolvimento do trabalho docente, no qual ocorrem inúmeros vínculos sociais entre os sujeitos, educadores e educandos. Nesse espaço desenvolve-se o processo de ensino sistematizado dos saberes culturais, sociais, econômicos e políticos que são construídos pela humanidade, organizados a partir de conteúdos curriculares determinados.

Tratar das práticas pedagógicas desenvolvidas em sala de aula demanda considerar algumas situações relevantes no espaço escolar, visto que este espaço não se apresenta com um meio isolado dentro do cenário educativo. Acontecem diversas questões no cotidiano escolar que interferem no desenvolvimento do trabalho pedagógico, isso exige que o professor também esteja em constante aprendizado. Não basta concluir a formação inicial e obter um título, é preciso se manter em formação. Para desenvolver as práticas pedagógicas que levem o educando ao aprendizado, o educador necessita ter um olhar crítico referente à realidade social, especialmente desses estudantes e da escola. Cabe a ele a elaboração, proposição e efetivação de ações pedagógicas que conduzam ao conhecimento.

Partimos da ideia de que o estudante precisa ser visto como sujeito da educação e não como um mero objeto de ensino. Para Freire (2017, p. 95) “o espaço pedagógico é um texto para ser constantemente lido, interpretado, escrito e reescrito", e ainda o autor afirma que é preciso ter solidariedade entre educador e educando. É importante compreender que a ação do professor tem uma ligação inseparável com o mundo real e, desse modo, para educar é necessário acolher bem os educandos, uma vez que é preciso "unir saber e experiência. A motivação para aprender está ligada ao sentido provocado pelo ato de ensinar" (CARVALHO, 2005, p. 185).

Entendemos que a formação continuada de educadores é uma das alternativas encontradas para discutir e refletir coletivamente sobre as práticas em sala de aula, promovendo a melhoria do trabalho docente e dos resultados esperados da educação escolar. Assim, 
pesquisas que evidenciem as relações entre a formação continuada e as práticas docentes são relevantes para as escolas e para as políticas educacionais.

Em Mato Grosso, a formação continuada tem sido parte importante da política da SEDUC, funcionando em todas as escolas da rede estadual um projeto de formação continuada que passou a ser chamado a partir de 2019 de Projeto de formação continuada da/na escola. A Seduc tem encaminhado documentos orientativos que direcionam a formação continuada, com as mudanças que entende serem necessárias. Atualmente, a proposta em vigor para a Formação Continuada tem como característica básica o estudo e a proposição de intervenções pedagógicas visando a melhoria da qualidade do ensino. Cada escola faz seu diagnóstico e constrói sua proposta de intervenção.

Este artigo está organizado em quatro seções além da introdução: Na primeira, discorremos sobre práticas pedagógicas e formação continuada; na segunda seção, evidenciamos os procedimentos metodológicos da pesquisa; na terceira seção apresentamos uma pesquisa de campo com reflexões acerca das intervenções pedagógicas desenvolvidas na escola pesquisada a partir da formação continuada; e por fim, na última seção, dispomos sobre as considerações analisadas neste estudo.

\section{PrÁticas PEDAgógiCAS E FORMAÇ̃̃o CONTINUAdA}

Compreendemos que a prática pedagógica é evidenciada a partir das atividades desenvolvidas no âmbito escolar, podendo ser atividades elaboradas com a intenção de promover a transformação ou visando a repetição/reprodução de conhecimentos. Com base em Paulo Freire podemos entender que práticas pedagógicas que visam apenas repetição ou reprodução são práticas que evidenciam a "educação bancária", no sentido de ser uma aprendizagem baseada no depósito de informação, sem o compromisso de levar o estudante a problematizar sua realidade. Freire (2019) fez diversas críticas à educação bancária, assim como criou uma proposta de educação libertadora, visando a transformação social, possibilitando ao educando transformar o senso comum em curiosidade epistemológica.

Segundo Veiga (1992, p. 16) a prática pedagógica é "uma prática social orientada por objetivos, finalidades e conhecimentos, e inserida no contexto da prática social. A prática pedagógica é uma dimensão da prática social". Sendo assim, é importante reafirmar que as práticas sociais estão tomadas de contradições socioculturais, tornando-se neste cenário um desafio aos educadores envolvidos, pois exige busca de aprendizagem constante, no quesito saber ouvir, falar, propor, mediar, contrapor e complementar. 
Franco considera que todo:

[...] encontro educativo tornar-se-á uma prática pedagógica quando se organizar em torno de intencionalidades, bem como na construção de práticas que conferem sentido às intencionalidades. Será prática pedagógica quando incorporar a reflexão contínua e coletiva, de forma a assegurar que a intencionalidade proposta é disponibilizada a todos (FRANCO, 2016, p. 10).

A autora afirma que o educador, ao acreditar que o seu trabalho proporciona a diferença na vida dos educandos, tem uma prática pedagógica fundamentada em teorias para melhorar o processo de ensino aprendizagem do educando. Dessa forma, a intencionalidade do docente, perpassa por influenciar o comportamento dos estudantes, insistindo na sua aprendizagem, dialogando e incentivando-os na construção do conhecimento.

A formação continuada para os professores da educação básica é um instrumento primordial, a qual entendemos ser promotora de mudanças significativas para o aperfeiçoamento da prática docente, bem como aprimoramento do conhecimento profissional. É um processo permanente de reflexão dos saberes docentes necessários para a realização da prática pedagógica. Os docentes podem discutir temas, solucionar problemas, possibilitando ressignificar sua prática pedagógica num constante movimento dialético entre teoria e prática. E ainda tornam-se preparados para propor estratégias com a finalidade de sanar dificuldades encontradas pelos estudantes no cotidiano escolar. Nesse sentido, destacamos as reflexões de Nóvoa (1992), onde afirma que a formação continuada deve pautar-se numa reflexão na prática e sobre a prática.

Imbernón defende uma formação continuada de professores que seja pautada no coletivo, valorizando o diálogo, o debate, a indagação e o trabalho em equipe, como forma de superar o individualismo no trabalho pedagógico. Ainda segundo o autor essa formação visa “[...] criar um clima de escuta ativa e de comunicação; elaborar projetos de trabalho em conjunto; superar as resistências ao trabalho colaborativo e conhecer as diversas culturas da instituição" (IMBERNÓN, 2010, p. 65).

$\mathrm{Na}$ escola pesquisada, a formação continuada é organizada a partir das necessidades formativas dos profissionais da educação, considerando a realidade da escola que atuam e a sua proposta pedagógica. Assim a formação continuada engloba:

[...] os processos através dos quais os professores - em formação ou em exercício se implicam [...] em equipe, em experiências e aprendizagem através das quais adquirem ou melhoram os seus conhecimentos, competências e disposições, e que lhes permite intervir profissionalmente no desenvolvimento do seu ensino do currículo e da escola, com o objetivo de melhorar a qualidade da educação que os alunos recebem. (MARCELO GARCIA, 1999, p. 24) 
Neste sentido, a formação continuada tem o intuito de contribuir para aperfeiçoamento das práticas pedagógicas permitindo ao docente implementar metodologias que contribuam para aprendizagem dos educandos.

Bitencourt (2017, p. 90) aponta que "ao refletir sobre sua ação, o professor dá significado às experiências vividas em sua prática docente e tem oportunidade de (re)construir saberes”. Por isso, a prática pedagógica deve estar alicerçada na formação continuada dos professores, visando reflexões das ações pertinentes à sala de aula num movimento ininterrupto.

É importante que o docente permaneça em constante processo de formação continuada buscando conhecimento, orientação, valorizando a investigação como estratégia de ensino, para com isso garantir uma prática pedagógica efetiva que promova aprendizagens significativas.

Freire (2017, p. 40) salienta "que na formação permanente de professores, o momento fundamental é o da reflexão crítica sobre a prática. É pensando criticamente a prática de hoje ou de ontem que se pode melhorar a próxima prática". Desse modo, ressaltamos que a formação continuada, se configura como um processo contínuo que leva a uma prática crítica-reflexiva da profissão, dando possibilidades de melhorar a prática pedagógica.

D`Ambrósio assevera que "entre teoria e prática persiste uma relação dialética que leva o indivíduo a partir para a prática equipado com uma teoria e a praticar de acordo com essa teoria até atingir os resultados desejados” (2002, p. 79). Dessa forma, buscar uma prática pedagógica voltada para um fazer que vise desenvolver nos educandos habilidades e capacidades de construir significados para investigar, analisar, criar estratégias, elaborar, interpretar e resolver problemas, dialética essa em que o papel do professor não se resume apenas em ministrar o conteúdo por meio de um saber engessado, o papel do professor, nesse contexto, é o de promotor do conhecimento, como pontua Freire (2017, p. 24) "ensinar é criar possibilidades para a sua produção ou a sua construção".

A formação continuada da/na escola realizada pelos professores da instituição pesquisada, tem uma grande importância, visto que ao participar da formação os professores tiveram momentos de estudos, que auxiliaram a compreender melhor o espaço escolar no qual trabalham, uma vez que a instituição está localizada no campo e que por isso podem e devem trabalhar com os educandos atividades pertencentes ao seu cotidiano, visando relacionar teoria a prática, o que influencia positivamente a aprendizagem dos estudantes, melhorando a qualidade da educação da referida instituição.

A formação continuada da SEDUC-MT está sob a responsabilidade da Superintendência de Formação dos Profissionais da Educação (SUFP) e por meio dos Centros de Formação e 
Atualização dos Profissionais da Educação Básica de Mato Grosso (CEFAPRO), tendo professores formadores nas áreas do conhecimento. Estes professores formadores realizam entre outros trabalhos o acompanhamento sistemático das formações continuadas nas escolas estaduais de Mato Grosso.

\section{Procedimentos Metodológicos}

Utilizamos como abordagem metodológica a pesquisa qualitativa que tem como preocupação "analisar e interpretar aspectos mais profundos, descrevendo a complexidade do comportamento humano. Fornece uma análise mais detalhada sobre as investigações, hábitos, atitudes e tendências de comportamento" (LAKATOS; MARCONI, 2004, p. 269). Esse método proporciona ao investigador um contato direto com os sujeitos ou grupos humanos investigados, favorecendo compreender suas falas, experiências e história.

A pesquisa foi realizada no ano letivo de 2019, na Escola Estadual Ivone Borkowski de Lima, localizada no campo, no Distrito Colorado do Norte, município de Nova Canaã do NorteMT. A escola ofertou ensino para uma turma do $8^{\circ}$ ano e uma turma da modalidade de Educação de Jovens e Adultos (EJA) multisseriada, ambas do ensino fundamental, quatro turmas do ensino médio regular e uma turma do ensino médio EJA multisseriada. A escola também possui uma sala anexa do ensino médio EJA multisseriada, totalizando oito turmas e 97 alunos matriculados no ano letivo de 2019. Ao todo foram oito professores que lecionaram no referido ano, porém sete trabalharam na escola sede e uma na sala anexa, a escola ainda possui um coordenador pedagógico e um diretor escolar. Assim, os sujeitos da pesquisa foram os sete docentes que lecionaram na escola sede, pois estes participaram da formação continuada realizada pela escola.

A formação continuada nesta instituição teve uma carga horária total de 80 horas no decorrer do ano letivo, sendo destinadas 60 horas para estudos teóricos e 20 horas para planejamento e socialização das atividades realizadas durante a intervenção pedagógica. Foi organizada pelo coordenador pedagógico, com participação dos sete professores e do diretor escolar, acompanhada por uma professora formadora do CEFAPRO do polo de Alta Floresta.

$\mathrm{Na}$ organização da pesquisa aqui analisada, fizemos observação direta nas atividades de formação continuada realizada na instituição, durante 10 encontros, correspondendo a 30 horas. Este foi o período em que os professores se dedicaram aos estudos teóricos para o desenvolvimento dos planejamentos e socialização das intervenções pedagógicas. Esse tipo de observação é utilizada "na medida em que o observador acompanha in loco as experiências 
diárias dos sujeitos, pode tentar aprender a sua visão de mundo, isto é, o significado que eles atribuem à realidade que os cerca e às suas próprias ações" (LUDKE; ANDRÉ, 2018, p. 31).

A análise documental foi realizada em três fontes: a) do orientativo do projeto de formação continuada da/na escola; b) o documento do Projeto Político Pedagógico (PPP) da escola; c) os relatórios das intervenções pedagógicas desenvolvidos pelos/as docentes.

\section{As intervenÇões Pedagógicas desenvolvidas Na ESCOLA SUSTENTAdas Pela FORMAÇÃO CONTINUADA}

Ao analisarmos o orientativo do projeto de formação continuada da/na escola elaborado pela SEDUC-MT em 2019 observamos que as escolas foram instruídas para realizarem um diagnóstico referente às necessidades formativas da unidade escolar, com a finalidade de superar as fragilidades e garantir a melhoria da qualidade da educação. O diagnóstico deveria ser elaborado a partir da dimensão "formação" do PPP da escola. ${ }^{1}$

A pretensão da SEDUC-MT foi possibilitar às escolas a consciência das suas realidades para elaborarem estratégias objetivando avançar no ensino e aprendizagem. O foco principal era desenvolver práticas pedagógicas embasadas em metodologias de ensino que fossem coerentes com necessidade dos estudantes. O documento enfatizou sobre a importância dos professores se atualizarem constantemente para desenvolver intervenções pedagógicas de acordo com as dificuldades de aprendizagem dos estudantes.

O orientativo esclarece que:

[...] a Intervenção Pedagógica é percebida como uma interferência realizada pelo professor ou por outros profissionais da educação no desenvolvimento da aprendizagem do sujeito ou grupo de sujeitos quando há evidências de problemas na aprendizagem, bem como outras demandas formativas dos estudantes que necessitam de ações pontuais para sua modificação (MATO GROSSO, 2019, p. 6).

De acordo com o orientativo, a intervenção pedagógica deve ser desenvolvida, a partir de metodologias diferenciadas, com o objetivo de realizar correções no processo de aprendizagem do sujeito, seja individual ou coletiva.

A intervenção pedagógica perpassa pelo planejamento, onde o docente deve elaborar as ações que serão desenvolvidas no decorrer de suas práticas pedagógicas, executar essas medidas definidas, que devem ter como objetivo a melhoria da aprendizagem dos estudantes, utilizando metodologias inovadoras que possam de fato contribuir para a construção do conhecimento, e

\footnotetext{
${ }^{1}$ Os PPPs das escolas estaduais de Mato Grosso seguem um modelo organizado por dimensões, sendo a formação dos profissionais uma delas.
} 
posteriormente, deve-se fazer uma avalição com o intuito de verificar se os objetivos propostos foram alcançados.

Após realizar o diagnóstico com base no PPP e demanda formativa apontada pelos profissionais da educação, os mesmos foram orientados a definirem as temáticas que fariam parte dos estudos teóricos, evidenciou-se sobre a importância de selecionar um campo teórico, favorecendo a elaboração e o desenvolvimento do plano de intervenção. O documento enfatizou a respeito da busca por "tendências contemporâneas de ensino e que contemplem metodologias inovadoras que possibilitem subsídios para o planejamento de intervenções pedagógicas em consonância com o seu PPP e com as políticas públicas educacionais" (MATO GROSSO, 2019, p. 10).

A partir do disposto no Orientativo, os docentes realizaram o diagnóstico e fizeram os apontamentos das necessidades formativas. De acordo com o projeto de formação continuada da/na escola, a instituição tem enfrentado problemas vinculados ao desinteresse dos educandos pelas atividades, baixa autoestima e, em alguns casos, situações de automutilação. As consequências dessas atitudes realizadas pelos alunos e apontadas pelos docentes estavam ocorrendo a desmotivação dos profissionais em inovar suas práticas pedagógicas. Outra problemática apontada é o desenvolvimento de práticas desvinculadas da realidade do educando, a escola tem desenvolvido apenas questões pontuais sobre alguns aspectos da comunidade.

Com base nas observações realizadas durante os encontros da formação continuada, pudemos acompanhar os profissionais elaborarem metas e estratégias para amenizar as necessidades formativas, e também selecionarem as temáticas teóricas para sustentar as intervenções pedagógicas. Apresentaremos algumas das metas e estratégias elaboradas para o ano letivo de 2019. Como metas elencaram: elevar o índice de aprovação do Ensino Médio para 100\%; zerar a progressão parcial; tornar o ambiente escolar mais agradável, atrativo e lúdico. Como estratégias: oportunizar recuperação para estudantes que não alcançarem o objetivo proposto; oportunizar aos estudantes uma aprendizagem mais significativa com conteúdos contextualizados à sua realidade; propiciar uma aprendizagem baseada em metodologias que explorem a capacidade de investigação, reflexão-ação, problematização e a autonomia dos educandos; assegurar a permanência dos estudantes nas práticas esportivas na escola; fortalecer as relações socioafetivas entre educadores e educandos com utilização de dinâmicas, jogos e brincadeiras. 
Para desenvolver o projeto de formação continuada 2019, os professores realizaram um diagnóstico do rendimento escolar do ano de 2018. Para isso foi feita uma análise dos dados da Ata de Resultados Finais do referido ano. Os dados mostram que dos 110 educandos matriculados, 79,09\% foram aprovados, 9,09\% reprovados e 11,81\% abandonaram. No ensino fundamental, a aprovação foi de $100 \%$ Já no ensino médio regular, obteve-se $85,71 \%$ de aprovação, 7,14\% de reprovação e 7,14\% de abandono. Nas turmas da Educação de Jovens e Adultos (EJA), esses índices foram 53,12\%, 18,75\% e 28,12\%, respectivamente. A partir da análise dos resultados, os docentes identificaram que houve retrocesso em relação ao ano anterior, com relação a aprovação, mas avanço no que tange ao abandono nas turmas da EJA, comparado com anos anteriores a 2017. O índice de aprovação principalmente no ensino médio, segundo os relatos dos professores na formação continuada, aconteceu devido à pouca participação dos educandos nas aulas, aparentando que estes precisavam se dedicar mais ao processo de aprendizagem. No caso da EJA existem outros fatores que interferem no índice de aprovação, pois alguns estudantes desistem de estudar devido à necessidade de ter que trabalhar e muitos encontram serviços distantes da escola, dificultando participarem das aulas.

Durante a formação continuada, os docentes realizaram estudos com o intuito de sustentar as intervenções pedagógicas, conforme observamos nos encontros em que participamos. Dentre as temáticas estudadas, destacamos os assuntos e os respectivos autores: planejamento (Libâneo, 1994); educação do campo (Machado, 2009 e Caldart 2009); práticas socioafetivas (Leite, 2008, Costa, 1997, Wallon, 1992, Vygostsky, 1992 e Piaget, 1992).

Os profissionais optaram por aprofundar os estudos sobre "planejamento" por acreditarem que este auxiliaria no desenvolvimento dos alunos, viabilizando meios para o sucesso do processo de ensino e aprendizagem. Segundo Libâneo (1994), o planejamento é um processo de racionalização, organização e coordenação do trabalho docente que propicia a articulação à atividade escolar e à problemática do contexto social.

O planejamento é um instrumento utilizado pelo professor que direciona seus passos no desenvolvimento de suas práticas, sendo que uma aula, quando planejada, possibilita ao professor e aos estudantes êxito no processo de ensino e aprendizagem. Ao elaborar um planejamento, o professor deve ter clareza quanto aos objetivos que se pretende alcançar, e ao final da sua execução deve-se verificar se os objetivos propostos foram alcançados.

Com relação à temática Educação do Campo, foi considerada necessária para promover práticas relacionadas à realidade da comunidade escolar. E conforme, relatado pelos professores, o estudo possibilitou ampliar os conhecimentos para organizarem as práticas 
pedagógicas conforme as concepções de Educação do Campo, dessa forma, possibilitaram aos estudantes vivenciar conteúdos, atividades, exercícios, relacionados ao seu cotidiano.

A organização da proposta pedagógica das escolas do campo, conforme Machado (2009) necessita ser baseada nos fundamentos filosóficos que sustentam a prática pedagógica da Educação do Campo. Tais princípios concebem “- as relações entre educação e trabalho, teoria e prática social; - a ação investigativa, questionadora e criativa; - as relações entre educação, cultura, política e economia; - o trabalho coletivo, a construção da autonomia dos coletivos de docentes e discentes, e a gestão democrática, dentre outros" (MACHADO, 2009, p. 8). Salientamos que estudos posteriores precisam ser realizados a respeito dessa temática, uma vez que a discussão é ampla e o tempo não foi suficiente para aprofundar no assunto.

Também estudaram as "práticas de abordagens socioafetiva", com o objetivo de descobrir maneiras para reduzir os atritos no ambiente educativo e proporcionar a motivação dos estudantes e dos educadores, esta dimensão configura-se em grande desafio.

De acordo com Leite (2008, p. 16), a dimensão afetiva não foi muito considerada como centralidade na constituição do ser humano, apesar de não ser negada. A humanidade herdou uma visão secular que o homem é dividido ente a razão e a emoção. Conforme Leite "durante séculos o pensamento dominante sempre caracterizou a razão como a dimensão mais importante, sendo a emoção, em vários momentos históricos, considerada o elemento desagregador da racionalidade, responsável pelas reações inadequadas do ser humano" (2008, p.16). Neste sentido, a razão tinha a função de dominar e controlar a emoção.

Esse modo de pensar teve grande influência no modo de organização curricular da escola, pois era dada maior ênfase nas "dimensões racionais/cognitivas no trabalho pedagógico" (LEITE, 2008, p. 17). No entanto, este conceito vem passando por transformações. O autor evidencia que a relação sujeito-objeto é definida pelo vínculo das dimensões cognitivas e afetivas. Isto é, a conexão que se apresenta entre o estudante e o conhecimento não é estabelecida apenas pelo cognitivo, mas também pelo afetivo, mostrando que quando o professor faz a mediação da aprendizagem a partir das práticas pedagógicas, deve se considerar a relação que se estabelece entre os sujeitos (professor e aluno) e o objeto a ser conhecido.

Para Leite (2008) a afetividade se constitui como:

[...] uma fator de grande importância na determinação da natureza das relações que se estabelecem entre sujeitos (alunos) e os demais objetos de conhecimento (áreas e conteúdos escolares), bem como na disposição dos alunos diante das atividades propostas e desenvolvidas. É possível, assim, afirmar que a afetividade está presente em todos os momentos ou etapas do trabalho pedagógico desenvolvido pelo professor[...] (LEITE, 2008, p. 24). 
Para o autor, a afetividade está associada às vivências e às maneiras de como as pessoas se expressam desde os sistemas simbólicos até a fala. Isso tudo possibilita "a transformação da emoção em sentimento e sua representação no plano interno, passando a interferir na atividade cognitiva e possibilitando o seu avanço" (LEITE, 2008, p.21). Almeida também reafirma que "a inteligência não se desenvolve sem afetividade e vice-versa, pois ambos compõem uma unidade de contrários" (ALMEIDA, 1999, p.29).

O que queremos evidenciar é que todas as intenções pedagógicas elaboradas pelo professor implicarão diretamente no aluno, tanto no nível cognitivo quanto no nível afetivo. Quando as ações pedagógicas facilitam o processo de aprendizagem levando o aluno a construir seus conhecimentos, entendemos que os objetos de conhecimento foram positivos. No entanto, quando as ações pedagógicas dificultam a aprendizagem tendo implicações negativas nas esferas afetivas, os alunos passam a ter aversão aos assuntos/conteúdos. Isso nos mostra que o fracasso ou o sucesso escolar dos educandos pode estar relacionado com questões ligadas a emoção e afetividade que podem implicar diretamente no seu aprendizado (cognitivo).

Nos encontros de formação continuada, os docentes apontaram como fatores de interferência na prática pedagógica o problema de desinteresse, baixa autoestima, descompromisso dos educandos com sua aprendizagem. Segundo os professores, isso tudo promove desmotivação do professor em buscar novas alternativas para melhorar sua prática, como dito anteriormente.

Com o objetivo de amenizar as problemáticas elencadas, os educadores resolveram desenvolver algumas intervenções pedagógicas voltadas para atender ao coletivo dos alunos. A primeira intervenção pedagógica com o grupo de estudantes foi a promoção de uma semana de jogos e brincadeiras na escola, com o objetivo de melhorar a autoestima, a concentração, a participação coletiva, a coordenação motora, a inclusão social, a disciplina, a linguagem corporal, verbal e visual dos estudantes da escola. Em um segundo momento, para fortalecer esse objetivo a escola decidiu participar dos "Jogos escolares da Educação do Campo", envolvendo todas as escolas do campo do município de Nova Canaã do Norte. Para a realização dos jogos foram utilizados dois finais de semana. Este evento esportivo foi organizado com recursos próprios das escolas envolvidas, estas promoveram eventos para arrecadar recursos para adquirir alimentação e premiação. Também houve parcerias com alguns comércios locais, pais e prefeitura municipal, ou seja, houve o envolvimento de toda a comunidade escolar para a realização dessa atividade. 
Nestas duas intervenções foram promovidos jogos individuais como, arremesso de dardo e peso, salto em distância, corrida de 75 metros e jogo de xadrez. E ainda, jogos coletivos, tais como: futsal, handebol, vôlei de quadra e vôlei de areia. Envolvendo os educandos do Ensino Médio, Ensino Fundamental e Educação de Jovens e Adultos - EJA.

Para Bento (1989), as atividades esportivas tem a intenção de proporcionar qualidade de vida, uma educação ética, moral e social, conhecimentos de habilidades e capacidades motoras que são importantes para a autonomia dos educandos. Segundo Paes (2002), é fundamental "aprender jogando" e não "aprender para jogar", uma vez que por meio das práticas esportivas surge um ambiente repleto de possibilidades e potenciais pedagógicos.

De acordo com os professores os jogos e brincadeiras contribuíram para o desenvolvimento do aprendizado dos educandos, pois os jogos coletivos e individuais permitem trabalhar os aspectos cognitivos, afetivos e socioculturais. Promovendo assim, a formação humana. Essas atividades foram importantes porque possibilitaram trabalhar questões comportamentais, disciplinares e de autoestima, uma vez que estes trouxeram diversos benefícios como convivência, inclusão, respeito, cooperação, aprender com os erros e lidar com as frustações. Por exemplo, os jogos escolares do campo possibilitaram aos estudantes conhecerem e competirem com pessoas diferentes, já que participaram dos jogos todas as escolas do campo do município, sendo cinco escolas (três municipais e 2 estaduais). E ainda, os alunos tiveram a oportunidade de visitar espaços diferentes, pois os jogos foram promovidos em dois espaços distintos. Sendo assim, conforme descrito por uma professora:

[...] a prática esportiva e os jogos proporcionaram a integração da maioria dos estudantes, a descoberta de talentos, bem como instigou a participação coletiva, cooperativa, inclusiva e também a competitividade; além de evidenciar a importância de compreender e valorizar habilidades distintas ou múltiplas inteligências dos estudantes, ou seja, alguns que se destacaram nas modalidades esportivas geralmente demonstram dificuldade de concentração ou desinteresse nas tradicionais aulas, já tem outros que são participativos e habilidosos nos dois contextos. Deste modo, os resultados foram positivos, porém na visão dos professores as intervenções precisam ter continuidade para que se alcance o máximo de resultados (V.K.M, 2019).

Outras intervenções realizadas para auxiliar na problemática com a finalidade de provocar a curiosidade e motivação dos educandos pela aprendizagem foram: palestras com psicóloga, psicopedagoga, fonoaudiólogo, com temáticas envolvendo bullying, prevenção contra drogas, suicídio, automutilação, entre outras. Os professores também desenvolveram diversas rodas de conversas, oportunizando aos educandos momentos para falarem sobre si próprios. 
Compreendemos que as palestras trouxeram resultados positivos, pois houve envolvimento dos estudantes durante a realização dessa atividade e no decorrer das aulas observou-se que os temas provocaram transformação no modo de pensar dos educandos. Conforme os professores, as rodas de conversas foram muito proveitosas, uma vez que abriram espaço para os alunos discutirem e sanar dúvidas sobre temas que em suas casas não são debatidos. Os docentes observaram que os jovens/adolescentes são muito carentes da atenção dos pais, a maioria se queixou que seus pais e/ou responsáveis não possibilitam momentos para conversarem sobre suas angústias, medos, anseios e sonhos e isso causa uma certa insegurança e desmotivação perante os seus estudos e desafios da vida.

Para auxiliar os educandos nos conteúdos que apresentaram mais dificuldades, os professores elaboram aulas com foco na revisão dos assuntos abordados, inclusive aulas de apoio pedagógico foram ministradas no contraturno para os educandos que, na percepção dos professores, necessitavam de maior apoio. As aulas de apoio pedagógico são uma grande aliada para o professor que deseja que seus alunos com dificuldades de aprendizagem, consigam compreender melhor determinados conteúdos que não foram assimilados durante a aula, pois nas aulas de apoio pedagógico o número de estudantes é reduzido, podendo ser até mesmo de apenas um aluno, e assim, o professor tem condições de dar total atenção a este aluno, revisando conteúdos, tirando dúvidas, corrigindo exercícios, entre outros.

Em todas as disciplinas os professores realizaram as intervenções necessárias, a seguir, discorremos sobre algumas.

Na disciplina de matemática os próprios estudantes confeccionaram jogos matemáticos, orientados pelo professor, que visavam auxiliar no desenvolvimento do raciocínio lógico, motivação, curiosidade, cálculo mental, entre outros benefícios que os jogos matemáticos podem trazer para melhorar a aprendizagem. Após a elaboração do material, os educandos começaram a jogar, realizando dentro da sala de aula pequenas competições. Conforme relatado pelo professor, essa atividade contribuiu de maneira significativa para despertar nos estudantes um maior interesse em estudar matemática, pois puderam perceber que a mesma está presente no nosso cotidiano.

Como a escola possui laboratório de informática com internet, os docentes, durante a intervenção pedagógica, planejaram aulas nesse ambiente, pois, por se tratar de uma escola do campo, a grande maioria dos estudantes não possui internet em casa, e esse ambiente era pouco explorado pelos docentes. Dessa forma, os alunos passaram a utilizar com mais frequência o laboratório de informática. Vale ressaltar que muitos têm a oportunidade de utilizar um 
computador somente na escola, pois não dispõem desse aparelho em casa, assim, muitos ficavam super ansiosos para ter aulas no laboratório.

Quanto à produção artística, contribuiu para a expressão de sentimentos, apreciação de belos trabalhos e socialização entre estudantes de turmas diversas. Para desenvolver a temática Vanguarda europeia, a professora desenvolveu aulas interdisciplinares entre artes e língua portuguesa. Promoveu inicialmente conversas sobre a temática, em seguida propôs pesquisa em livros, site e blogs de textos e vídeos, e solicitou a produção de mapa mental ${ }^{2}$ das correntes estudadas, podendo utilizar palavras-chave e/ou emojis. Os estudantes foram divididos em grupos para a distribuição das temáticas: Futurismo, Cubismo, Expressionismo, Dadaísmo, Surrealismo. Após estudos e pesquisas, foi realizado um seminário para apresentação e socialização das produções feitas por cada grupo. Também foram realizadas dinâmicas que relacionassem recortes de pinturas, esculturas, arquiteturas diversas as correntes correspondentes sem consultar qualquer material ou colega.

De acordo com a professora esta intervenção pedagógica com o trabalho coletivo trouxe excelentes resultados para a aprendizagem, pois proporcionou maior socialização e envolvimento dos educandos no processo de ensino e aprendizagem.

Nas disciplinas envolvendo a área de ciências da natureza a professora expôs que desenvolveu uma prática por meio da produção de duas receitas de sabão caseiro. Nestas receitas utilizou os seguintes elementos: limão, gordura/óleo usado, soda cáustica, suco de uva, sabão ipê e sal de cozinha. A partir destas práticas a professora pode explorar com os educandos assuntos sobre substâncias químicas, transformações químicas, propriedades da matéria, que são assuntos em que os alunos apresentaram dificuldades. Foram realizadas também práticas envolvendo primeiros socorros, para que os alunos aprendessem as primeiras providências em relação a parada cardíaca, queimadura, afogamento, picada de animais e outros. Tais intervenções foram desenvolvidas com a finalidade de proporcionar aos estudantes do Ensino Médio uma aprendizagem mais significativa com conteúdos contextualizados à sua realidade e as mesmas apresentaram resultados positivos, visto que os alunos mostraram maior interesse pelos assuntos estudados e conseguiram assimilar os conteúdos com mais facilidade.

Todas as intervenções pedagógicas realizadas na escola tiveram como objetivo a melhoria da aprendizagem dos estudantes, e para isso foram traçadas três metas. Na primeira

\footnotetext{
${ }^{2} \mathrm{O}$ mapa mental é um diagrama construído para caracterizar ideias, atividades ou outras definições que estão relacionados com uma palavra-chave ou uma ideia central, e cujas informações relacionadas em si são emitidas em seu entorno.
} 
meta, que consistiu em elevar o índice de aprovação do ensino médio para 100\%, o resultado foi o seguinte: em 2018 a escola possuía um índice de 85,71\% de aprovados no ensino médio. Em 2019, a escola atingiu um índice de aprovação de 93,75\% dos alunos matriculados no ensino médio, porém essa porcentagem aumenta para 95,60\% quando consideramos somente a escola sede que inclui educandos do ensino regular e EJA, se levarmos em consideração somente o ensino médio regular, obteve-se um índice de $100 \%$ dos estudantes do ensino médio aprovados em 2019. Dessa forma, as intervenções pedagógicas realizadas pelo corpo docente da escola pesquisada, foram eficientes para conseguir aumentar o índice de aprovação. Apesar da mudança de resultados nunca é possível afirmar que todos eles são fruto das intervenções pedagógicas realizadas, assim, é possível afirmar que os dados apontam melhoras nos índices, e que talvez sejam resultados das intervenções ou que elas devem ter colaborado para isso Mas não há dados que permitam medir a eficiência delas, não há como verificar causa e efeito tão diretos.

Com relação a segunda meta que se tratava de zerar a progressão parcial, o resultado foi o seguinte: em 2018, a porcentagem de estudantes que se encontravam com dependência em alguma disciplina foi de 19,64\%. Em 2019, a escola conseguiu diminuir este índice para 8,7\%. Não conseguiram zerar as progressões, mas obtiveram um resultado satisfatório, diminuindo os educandos que possuíam alguma dependência.

No que se refere à terceira meta, que era de tornar o ambiente escolar mais agradável, atrativo e lúdico, na percepção dos professores esse objetivo foi alcançado, visto que, conseguiram proporcionar momentos de diversão, alegria, parceria, coletividade, comunicação e cooperação, além de fortalecer as relações socioafetivas. Pois até mesmo educandos que não eram muito participativos, passaram a participar das brincadeiras, jogos e atividades propostas, mesmo que de forma tímida.

\section{CONSIDERAÇões FINAIS}

No desenvolvimento desta pesquisa as análises foram realizadas cotejando os dados referentes aos problemas detectados pelo diagnóstico, aos estudos feitos na formação continuada, às metas propostas, às práticas pedagógicas efetivadas e aos resultados obtidos. Evidenciamos que as intervenções pedagógicas realizadas pelos docentes no ano letivo de 2019, contribuíram significativamente para a melhoria no processo de ensino e aprendizagem da instituição, visto que algumas metas foram definidas, e posteriormente ações foram realizadas para atingir os objetivos propostos. 
As teorias estudadas, discutidas e refletidas durante a formação continuada da/na escola possibilitaram aos professores bases para elaborarem e aplicarem as intervenções pedagógicas nas salas de aulas, visto que o intuito da referida formação foi contribuir para a melhoria das práticas pedagógicas, realizando reflexão sobre o desenvolvimento do trabalho realizado. Dessa forma, pautando-se na teoria, foi possível aperfeiçoar as práticas pedagógicas, implicando diretamente na melhoria da qualidade da educação. Destarte, evidenciou-se que o projeto formação continuada da/na escola foi construído a partir das necessidades reais do cotidiano escolar a fim de atender as necessidades formativas, valorização do saber e a experiência dos estudantes, integrando de forma eficaz, teoria e prática. Outros estudos podem ser realizados para compreensão mais aprofundada dos processos trabalhados.

O desenvolvimento das práticas pedagógicas envolve desde a organização, estruturação e intencionalidade, pois o professor deve insistir na aprendizagem, incentivando os estudantes na produção e construção do conhecimento. Dessa forma, evidenciamos que as intervenções pedagógicas realizadas na escola em foco, pautaram-se na intencionalidade, visto que os docentes realizaram ações que proporcionaram melhoria na aprendizagem, eles incentivaram, dialogaram, estimularam o raciocínio, oportunizaram aulas de apoio pedagógico, entre outras ações. Ressaltamos que as práticas pedagógicas precisam ser modificadas e adaptadas constantemente para dar conta das transformações ocorridas na sociedade. Pois, conforme Franco (2012, p. 158), “as práticas pedagógicas são práticas que se constroem para organizar determinadas expectativas de uma grupo social". Segundo a autora estas "deverão reorganizarse e recriar-se a cada dia para dar conta do projeto inicial, que se vai transmudando à medida que a vida, o cotidiano, a existência o invadem. Não há projeto pronto; não há práticas prontas. (FRANCO 2012, p.164)

Durante os encontros de formação os professores avaliaram as intervenções pedagógicas trabalhadas e enfatizaram que as atividades esportivas e de brincadeiras foram valiosas para o desenvolvimento dos educandos, uma vez que contribuíram para auxiliar no comportamento dos estudantes, pois o esporte exige que respeitem regras, aprendam a lidar com as diferenças, as frustações e a disciplina. Na socialização, favoreceu para agrupar diversos estudantes, que assim tiveram a oportunidade de fazer novos amigos, valorizar o sentimento de solidariedade e companheirismo, auxiliando para uma boa convivência em grupo. O esporte tornou-se um importante aliado na busca de fundamentos de participação, coletividade, cooperação e de valores éticos, morais e sociais, proporcionando aos educandos uma formação de cidadãos críticos e preparando para os desafios da sociedade. 
De modo geral, os professores consideraram que as intervenções alcançaram resultados esperados principalmente avanços em questões relativas às relações intra e interpessoais e à capacidade de concentração dos estudantes. Nesse sentido, os profissionais expressaram no planejamento a expectativa de proporcionar a melhora da afetividade, concentração, da inclusão, da participação coletiva e também da disciplina no ambiente escolar.

Em síntese, de acordo com a opinião dos professores a escola pesquisada desenvolveu no ano letivo de 2019 ações que contribuíram para a melhoria do ensino e aprendizagem, uma vez que as metas que foram traçadas para a intervenção pedagógica, tiveram a maioria dos seus objetivos alcançados.

Como já mencionamos as informações aqui discutidas partiram da análise apresentada no projeto de formação continuada e nas observações realizadas nos encontros. No entanto, o que nos chamou a atenção é que, apesar de apontarem no diagnóstico a necessidade de práticas voltadas à realidade do educando, praticamente não observamos ações/intervenções direcionadas com temáticas envolvendo, por exemplo: agroecologia, sustentabilidade, economia camponesa, trabalho, assuntos relacionados ao campo, local de vida da comunidade escolar, voltados à Educação do Campo, conforme diretrizes educacionais para esta modalidade. Segundo Zart (2012, p. 245), a Educação do Campo deve promover "o desenvolvimento do conhecimento científico, em diálogo com os saberes das experiências camponeses, para registrar, ampliar e aprofundar os conhecimentos que apreendam a complexidade do campo, ou da correspondência entre o trabalho e o cuidado".

\section{REFERÊNCIAS}

ALMEIDA, Ana Rita Silva. A emoção na sala de aula. Campinas: Papirus, 1999.

BITENCOURT, Loriége Pessoa. Aprendizagem da docência do professor formador de educadores matemáticos. Curitiba: CRV, 2017

BENTO, Jorge. Olímpio. A criança no treino e desporto de rendimento. Revista Kinesis, Santa Maria, v. 5, n. 1, p. 9-35, 1989. Disponível em:

https://periodicos.ufsm.br/kinesis/article/view/8518/0. Acesso em 18 abr. 2020.

CARVALHO, Ademar de Lima. Os caminhos perversos da educação: a luta pela apropriação do conhecimento no cotidiano da sala de aula. Cuiabá: EdUfmt, 2005.

D`AMBROSIO, Ubiratan. Educação Matemática: Da teoria à prática. 9a ed. Campinas: Papirus, 2002.

FRANCO, Maria Amélia do Rosário Santoro. Pedagogia e prática docente. 1. ed. São Paulo: Cortez, 2012. 
FRANCO, Maria Amélia do Rosário Santoro. Prática pedagógica e docência: um olhar a partir da epistemologia do conceito. Rev. bras. Estud. pedagog. (on-line), Brasília, v. 97, n. 247, p. 534-551, set./dez. 2016. Disponível em:

https://www.scielo.br/pdf/rbeped/v97n247/2176-6681-rbeped-97-247-00534.pdf. Acesso em: 17 mar. 2020.

FREIRE, Paulo. Pedagogia do Oprimido. 71. ed. RJ/São Paulo: Paz e Terra, 2019.

FREIRE, Paulo. Pedagogia da autonomia: saberes necessários à prática educativa. $55^{\mathrm{a}}$ ed. Rio de Janeiro/ São Paulo: Paz e Terra, 2017.

IMBERNÓN, Francisco. Formação continuada de professores. Tradução Juliana dos Santos Padilha. Porto Alegre: Artimed, 2010.

LAKATOS, Eva Maria; MARCONI, Marina de Andrade. Metodologia Científica. 4.ed. São Paulo: Atlas, 2004.

LEITE, Sérgio Antônio da Silva. Afetividade e práticas pedagógicas. 2. ed. São Paulo: Casa do Psicólogo, 2011.

LIBÂNEO, José Carlos. Didática. São Paulo: Cortez, 1994.

MACHADO, Ilma Ferreira. Um projeto político pedagógico para escolas do campo.

Cadernos de Pesquisa: Pensamento Educacional v.4 no 8, jun. / dez. p. 191-229, 2009.

Disponível em: https://seer.utp.br/index.php/a/article/view/1911. Acesso em 16 mar. 2020

MATO GROSSO. Orientativo do projeto de formação da/na escola. SEDUC/MT, Cuiabá, 2019.

MARCELO GARCIA, Carlos. Formação de professores: para uma mudança educativa. Porto: Porto editora, 1999.

NÓVOA, Antonio (org.). Professores e a sua formação. Lisboa: Dom Quixote, 1992.

PAES, Roberto Rodrigues. Pedagogia do esporte e os jogos coletivos. In: DE ROSE JUNIOR, Dante. Esporte e atividade física na infância e na adolescência. Porto Alegre: Artmed, 2002. p. 89-98.

VEIGA, Ilma Passos Alencastro. A prática pedagógica do professor de Didática. 2. Ed. Campinas: Papirus, 1992.

ZART, Laudemir Luiz. Produção social do conhecimento na experiência do Curso de Agronomia dos Movimentos Sociais do Campo (CAMOSC): interação da UNEMAT e de Movimentos Sociais do Campo. 2012. 397f. Tese (Doutorado em Política Científica e Tecnológica) - Instituto de Geociências, Universidade Estadual de Campinas, Campinas, 2012. Disponível em:

http://repositorio.unicamp.br/bitstream/REPOSIP/286894/1/Zart_LaudemirLuiz_D.pdf. Acesso em: 25 abr. 2020.

Recebido em: 9 de junho de 2020.

Aprovado em: 24 de agosto de 2020. 